\title{
Rebeldía objetual en tiempos de des-normalización de la funcionalidad
}

Object rebellion in times of de-normalization of functionalities

\section{SEBAstián TEDEsco}

Universidad Nacional de Tres de Febrero, Depto. De Arte y Cultura, Argentina.

\section{Resumen}

Un recorrido teórico y una reflexión sobre el arte y el diseño, así como un diálogo entre obras de artistas argentinos contemporáneos que se vinculan a través de una sintaxis común entre ellas, una sintaxis basada en operaciones y estrategias de negación de la funcionalidad original de los objetos, funcionalidades que operan desde un modelo que nos fue inculcado, en donde los objetos nos deben servir, obedecer y ser bellos. Estos son objetos que luchan con su condición de modelo, su condición canónica o normativa, son al mismo tiempo reales y representados, objetos y cosas, estáticos y dinámicos. Son objetos que nos ofrecen una mirada sobre las transformaciones experimentadas dentro de la cultura material de la vida cotidiana. Ellos nos ayudan a reconocer ciertos aspectos concretos que distinguen la vida de las personas y a convertir las situaciones particulares y sociales en experiencias plausibles de ser narradas.

Artículo original

Original Article

Correspondencia/

Correspondence

Sebastian Tedesco

stedesco@untref.edu.ar

Financiación/Fundings

Sin financiación

Received: 30.08.2021

Accepted: 08.11.2021

PALABRAS CLAVE: objetos de uso, diseño, arte contemporaneo, negación de la funcionalidad, sintaxis objetual.

CÓMO CITAR ESTE TRABAJO / HOW TO CITE THIS PAPER

TEDESCO, S. (2021). Rebeldía objetual en tiempos de des-normalización de la funcionalidad. Umática. Revista

sobre Creación y Análisis de la Imagen, 4.

https://doi.org/10.24310/Umatica.2021.v3i4.13357

Umática. 2021; 4. https://doi.org/10.24310/Umatica.2021.v3i4.13357 


\title{
Object rebellion in times of de-normalization of functionalities
}

\section{SEBAstián TEDEsco}

Universidad Nacional de Tres de Febrero, Depto. De Arte y Cultura, Argentina.

\begin{abstract}
A theoretical journey and thoughts on art and design, as well as a dialogue between works by contemporary Argentine artists that are linked through a common syntax between them, a syntax based on operations and denial strategies of the original functionality of the objects, functionalities that operate from a model that was instilled in us, where objects must serve us, obey and be beautiful. These are objects that struggle with their role model, their canonical or normative condition, they are at the same time real and represented, objects and things, static and dynamic. They are objects that offer us a look at the transformations experienced within the material culture of everyday life. They help us recognize certain concrete aspects that distinguish people's lives and turn particular and social situations into plausible experiences to be narrated.
\end{abstract}

KEY WORDS: objects of use, design, contemporary art, negation of functionality, object syntax.

\section{Summary - Sumario}

Rebeldía objetual en el arte contemporáneo argentino

Duración Interna de Pablo Accinelli (2018)

Sin titulo, de Carlos Herrera (2010/2011)

Trap, de Jorge Macchi (2018)

Las Herramientas de Moisés, de Gabriel Baggio (2017)

Reacción, de Jorge Macchi (2010)

La voz del interior, de Andrés Aizicovich (2016)

Sin título, de Ernesto Ballesteros (2017)

Morir no es posible, de Mariana Telleria (2013)

Sin titulo (estructura para mesita) (2010) y Powerful lessons, (2015), de Eugenia Calvo $4 \mathrm{~cm}, 9 \mathrm{~cm}$, y $6 \mathrm{~cm}, 3 \mathrm{~cm}$, de Pablo Accinelli (2018)

Conclusiones 
Desde mediados del siglo XX el diseño industrial ha ocupado un lugar central en nuestra cotidianeidad al ser una parte instrumental fundamental de la gestación del mundo objetual que nos rodea. Este universo de objetos ordinarios propone inagotables capas de sentido y posibilidades que lo constituyen como un espacio temático, conceptual y operativo ineludible para gran cantidad de artistas.

Tradicionalmente la idea de 'objeto' refiere a la idea de objeto artificial asociada a la fenomenología de la vida cotidiana, un 'objeto de uso' en tanto que la idea de 'uso' lo diferencia del resto de las 'cosas'. Para adecuar esta idea de objeto a nuestro contexto contemporáneo debemos afirmar que la materialidad de un objeto podría estar constituida por información, en la medida que la misma es representada ante nuestros sentidos en reemplazo de un objeto de una materialidad de naturaleza no informática (Ej:: una aplicación informática que reemplaza al objeto físico ante los sentidos en términos similares de forma y función, o un objeto en una realidad virtual o aumentada). También podríamos considerar la posibilidad de un objeto de materialidad híbrida o mixta entre un plano material y un plano informativo o digital, así como también objetos que se gestan y fabrican así mismos como en el caso de la inteligencia artificial y la fabricación digital. Todas estas posibles variantes materiales y conceptuales, derivadas de la materialidad ampliada que proponen los medios digitales (en su camino hacia la colonización de territorios que antes les eran ajenos) provocan una problematización de las metodologías proyectuales a través de las cuales el diseño se ocupaba de entender su campo de acción y aplicación en relación a los objetos, especialmente la concepción de los conceptos que luego encarnan en los objetos desarrollados.

Una de las particularidades que ofrece el objeto de uso, como objeto artístico entre los demás objetos, es su cualidad interfacial y ambigua. Los objetos de uso, desde la mirada de las prácticas artísticas contemporáneas, luchan contra su condición de modelo, su condición canónica o normativa: son, al mismo tiempo, reales y representados, objetos y cosas, estáticos y dinámicos. Actualmente es usual, en las escenas del arte contemporáneo, ver obras y artistas que trabajan desde de la creación, re-configuración, intervención y puesta en relación de objetos de uso cotidiano, a tal punto que se puede vislumbrar, quizás, la posible existencia de una sintaxis objetual común entre ellos. Una sintaxis que podría estar basada en las infinitas tipologías y estrategias imaginables para negar o cuestionar la funcionalidad original de cada objeto, funcionalidades que operan desde un modelo canónico o normativo que nos fue inculcado, en donde los objetos nos deben servir, obedecer y ser bellos.

Otro eje importante para analizar este fenómeno es el aparente antagonismo entre las incumbencias del arte y del diseño, entre las bellas artes y las artes aplicadas o 'decorativas'. Por un lado, el pensamiento contemporáneo sobre el tema del objeto, especialmente en relación al objeto artístico, pone en juego, cuestiona y problematiza la supuesta primacía de la funcionalidad y de los aspectos materiales como parámetro para establecer la relación que el hombre tiene con ellos. Por otro lado, el diseño industrial mira al objeto y a su gestación desde una teoría caracterizada por la racionalidad que, en general, se define en oposición al pensamiento y la práctica artística. 
En el 2006, con motivo de los 50 años Escuela Superior de Diseño de Ulm, Dagmar Rinker escribe un ensayo titulado "El diseño de producto no es arte", dedicado al aporte de Tomás Maldonado al surgimiento de lo que en 1958 era un nuevo perfil profesional en el campo del diseño de objetos. El surgimiento de los métodos industriales de producción hizo necesaria la separación de la actividad del diseño para ponerla en manos de especialistas que, hasta mediados del siglo XX, provenían de los grupos profesionales de arquitectos, ingenieros y artistas hasta que la Bauhaus dio el giro decisivo en el campo del diseño de productos industriales. Maldonado declaraba la necesidad de distanciarse de las premisas artísticas en el campo del diseño para orientarse a la introducción de un pensamiento científico-operacional y una metodología objetivista-experimental (Rinker, 2006).

A partir de los postulados de Maldonado y el 'modelo de Ulm', el diseño industrial estuvo marcado por la doctrina del funcionalismo durante varias décadas hasta los años ochenta, en donde se introducen las ideas del post-modernismo y diversas críticas al funcionalismo. En el campo del diseño esta crítica toma forma con la aparición de diversos movimientos (como, por ejemplo, el Diseño Radical italiano) desde los cuales se buscaron otros planteamientos proyectuales que no se orientaron ya a las exigencias de la producción en serie, ni tampoco a la satisfacción de las necesidades humanas sino, fundamentalmente, a la expresión individual del espíritu de la época (Bürdeck, 2002).

Boris Groys, en su libro Volverse Público, dedica el capítulo "La obligación del diseño de si" al análisis de la centralidad del diseño en la vida contemporánea. Toma como punto de partida el origen del diseño modernista como ruptura y cambio paradigmático en relación a su propia tradición (su conexión con el arte y lo artesanal) y explica la dirección que tomó el diseño moderno hacia la búsqueda de una esencia escondida de las cosas en desmedro de sus superficies (un diseño negativo o un antidiseño). Según el autor, el diseño moderno esta profundamente ligado al proyecto de rediseñar al 'hombre viejo' como 'Hombre Nuevo', un proyecto utópico que nunca fue abandonado y que, de una forma modificada y comercial, continúa teniendo efecto. La forma última del diseño es, por lo tanto, el diseño del sujeto. Con la aparición del diseño la ética se volvió estética, se volvió forma y entonces el sujeto moderno tenía ahora la obligación del autodiseño, su presentación estética como sujeto ético. Así como se espera que el hombre moderno se presente a sí mismo como un objeto honesto, sin diseño, de igual modo, las cosas que lo rodean también deberían presentarse como honestas y sin diseño. Esa síntesis se alcanzaría eliminando las cosas que parecían muy artísticas, tanto del arte como de la vida. Sin embargo, al asumir una responsabilidad ética y estética, los consumidores se convierten en prisioneros del diseño total, porque ya no pueden delegar en otro las decisiones estéticas, cada uno se vuelve un artista/diseñador que tiene una responsabilidad ética, política y estética con su propio entorno (Groys, 2014).

Este brevísimo repaso sobre los orígenes del diseño, sus encuentros y desencuentros en relación al arte, son importantes en varios sentidos. Por un lado, es necesario el entendimiento sobre cómo el 'modelo de Ulm' y el funcionalismo han operado en los objetos de uso que 
conocemos (y siguen operando actualmente en la práctica del diseño) para poder tener una referencia clara de los discursos, debates y relatos implícitos en los objetos que habitan estas obras de arte contemporáneo que nos interesan: esos mandatos y modelos normativos que se establecen para el comportamiento funcional de los objetos de uso. Por otro lado, para poder entender de qué forma estas prácticas artísticas contemporáneas podrían hacer algún tipo de aporte a la disciplina del diseño, es necesario entender y confrontar las dificultades que, en ese sentido, plantea el pensamiento actual en relación al diseño. Señalar que lo que está en juego para los defensores del modernismo y racionalismo en el campo del diseño es la defensa de un proyecto filosófico, ético y político marca con más precisión, y es fundamental, para comprender el escenario en el que se mueven estas producciones artísticas.

Paralelamente al pensamiento desde el campo del diseño, el investigador y curador Anthony Hudek desarrolla un marco teórico e historiográfico en torno al pensamiento contemporáneo sobre el tema del 'objeto' desde la producción artística a partir del recorrido por las ideas de diversos autores en "The Object. Documents of Contemporary Art" de 2014. Hudek inicia su trabajo definiendo la idea heideggeriana de 'objeto' a partir de la oposición o contraste con la idea de 'cosa', que se propone como más amplia que el objeto, pero también más esencial. Sin embargo, a comienzos del siglo XX, Edmund Husserl, a través de la llamada 'fenomenología de Husserl', descartó la existencia de una cosa en sí misma, que estaría más allá del alcance intencional de los sujetos. Para Husserl los objetos, independientemente de su naturaleza material, sólo pueden percibirse a través de sus fenómenos y sus 'formas de entrega' a la conciencia (Hudek, 2014).

Otro encuadre teórico, para estas obras que proponen o presentan este tipo de objetos, podría encontrarse en lo que Rosalind Krauss definió en 1999 como la 'condición post-media'. Esta idea argumenta que la era de los medios discretos e identificables ha pasado. Pero Krauss, en su definición, paradójicamente, retiene la palabra 'medio' para abrir su campo discursivo a otras posibilidades (como podrían ser el diseño o los objetos de uso). Una práctica que libera las cosas de la esclavitud de la utilidad, un tipo de operación que, a diferencia del readymade Duchampiano, se puede referenciar en el trabajo de Andy Warhol y Marcel Broodthaers, que utilizan la técnica de la re-visualización de objetos para crear una sensación de alejamiento en el sujeto, convirtiendo al autor y al espectador en cosas. Los medios empleados por Broodthaers y Warhol no son tecnológicos, en el sentido de 'nuevos medios'; más bien son 'soportes técnicos', como los llama Krauss. Independientemente de sus cualidades físicas, el soporte técnico permite que "el artista descubra sus 'reglas' que, a su vez, se convertirán en la base de esa auto-evidencia recurrente de la especificidad de los medios" (Hudek, 2014).

Estas ideas contemporáneas sobre el objeto son necesarias para comprender las condiciones sobre las cuales los artistas que trabajan con objetos de uso desarrollan su obra, condiciones que habilitan a los objetos a ser libres y recuperar su derecho a ser, liberados de la dictadura del sujeto, desenfocándose de su mandato productivo y desestabilizando al sujeto/ 
receptor que hubiera querido que esos objetos sirvieran para algo. Son el contexto desde el cual los artistas que trabajan con objetos de uso pueden suspender a sus objetos en un tiempo sin trabajo desde donde desarrollar otros vectores de sentido y, quizás, de utilidad.

Por lo tanto, estas ideas sobre el objeto como una 'cosa' autónoma en sí misma, la 'seriedad' de un objeto, la 'cosa' como la ocultación de un secreto no disponible para los objetos y los sujetos, la 'cosa', como punto ciego, parece haberse simultáneamente acercado (en la medida en que puede percibirse intuitivamente) y alejado del dominio perceptivo del sujeto. Esta dinámica provoca la sensación de estar, como sujetos, permanentemente alejándonos y acercándonos, al mismo tiempo, a los objetos y generando relaciones para los sujetos que circulan alrededor de ellos. Esta intermediación por parte del objeto conduce a una nueva conciencia de la objetivización inherente de nuestro mundo, en donde, como sujetos, participamos en redes de objetos cada vez más densos y volátiles.

Para Jean Baudrillard, desde la perspectiva del 'sistema de los objetos', lo 'funcional' adquiere un significado que nos es útil para comprender y pensar lo que sucede con estas producciones artísticas:

Colores, formas, materiales, colocación, espacio, todo es funcional. Todos los objetos pretenden ser funcionales, como todos los regímenes tienden a ser democráticos. Ahora bien, este término, que encierra todos los principios de la modernidad, es perfectamente ambiguo. Derivado de 'función', sugiere que el objeto se consuma en su relación exacta con el mundo real y con las necesidades del hombre. De hecho, de los análisis anteriores se desprende que 'funcional' no califica de ninguna manera lo que está adaptado a un fin, sino lo que está adaptado a un orden o a un sistema: la funcionalidad es la facultad de integrarse a un conjunto. Para el objeto, es la posibilidad de rebasar precisamente su 'función' y llegar a una función segunda, convertirse en elemento de juego, de combinación, de cálculo en un sistema universal de signos (Baudrillard, 1969, p. 71).

Este concepto de lo funcional que propone Baudrillard se independiza de los principios de la modernidad en tanto un atributo del objeto de uso direccionado por la mano del diseñador hacia un fin eficaz, adecuado a sus fines, para pasar a ser parte de un sistema de signos, en relación a otros signos, en la construcción de nuevos significados en el rebasar la función del objeto. Esta concepción de funcionalidad es central para entender muchos de los mecanismos y abordajes de los artistas en relación a los objetos de uso en sus obras y para pensar de qué manera la participación del arte podría aportar al campo del diseño.

Otro concepto importante para entender el lugar de los objetos de uso en la obra artística es el de 'representación'. Para Ernst H. Gombrich la idea de 'representación' no trata so- 
bre la idea de imitar o retratar algo real, sino que viene a constituir el sustitutivo de eso, su re-presentación. Gombrich plantea que entender la representación como niveles de abstracción de las formas originales del objeto representado es problemática ya que, como la mente humana actúa por diferenciación más que por generalización, esta relación puede llevar a equívocos y ambigüedades. Por lo tanto, la idea que quiere elaborar Gombrich en relación a la representación es, más que la capacidad de vincular la imagen a una realidad, ya sea imaginaria o efectiva, es su capacidad de ser testimonio de una experiencia específica, de representar el sentido en el que las imágenes y los objetos pueden ser sustitutivas. De esta manera un atributo común entre dos cosas puede sustituir una por otra y convertirse una en representación de la otra a pesar de su aspecto formal. Un palo se puede montar y por lo tanto sustituir al caballo, aquí la funcionalidad de 'montable' funciona como atributo sustituyente, como símbolo de lo que representa (Gombrich, 1963).

Teniendo en cuenta que nos interesan las obras que trabajan con objetos de uso, esta idea de representación, esta posibilidad de separar la idea de representación de los conceptos que la asociaban restringidamente a la mímesis y a la abstracción formal es fundamental, ya que coloca al uso o función de lo representado en un lugar central, dentro de las posibilidades semánticas de la particular poética objetual que cada artista desarrolla.

\section{Rebeldía objetual en el arte contemporáneo argentino}

Para ilustrar estas ideas sobre formas de rebeldía y emancipación de objetos en manos de los artistas, se analiza una selección de obras de artistas argentinos contemporáneos que se vinculan a través de una sintaxis común, pero desde la cual cada artista despliega su propia y particular poética objetual, y que les permite reflexionar y problematizar cuestiones que tienen que ver tanto con la vida en el hogar y el ámbito de lo privado como también con la vida laboral y lo social. Son obras que presentan la aplicación de una serie de operaciones formales que constituyen algunas estrategias o tipologías de negación de la funcionalidad normativa de los objetos de uso:

- Negación por hibridación de dos funcionalidades.

- Negación por materialidad no apta.

- Negación por situación de reposo ordenado.

- Negación por re-funcionalización de objetos en secuencia.

- Negación por desmembramiento y re-configuración.

- Negación por restricción física de la funcionalidad. 


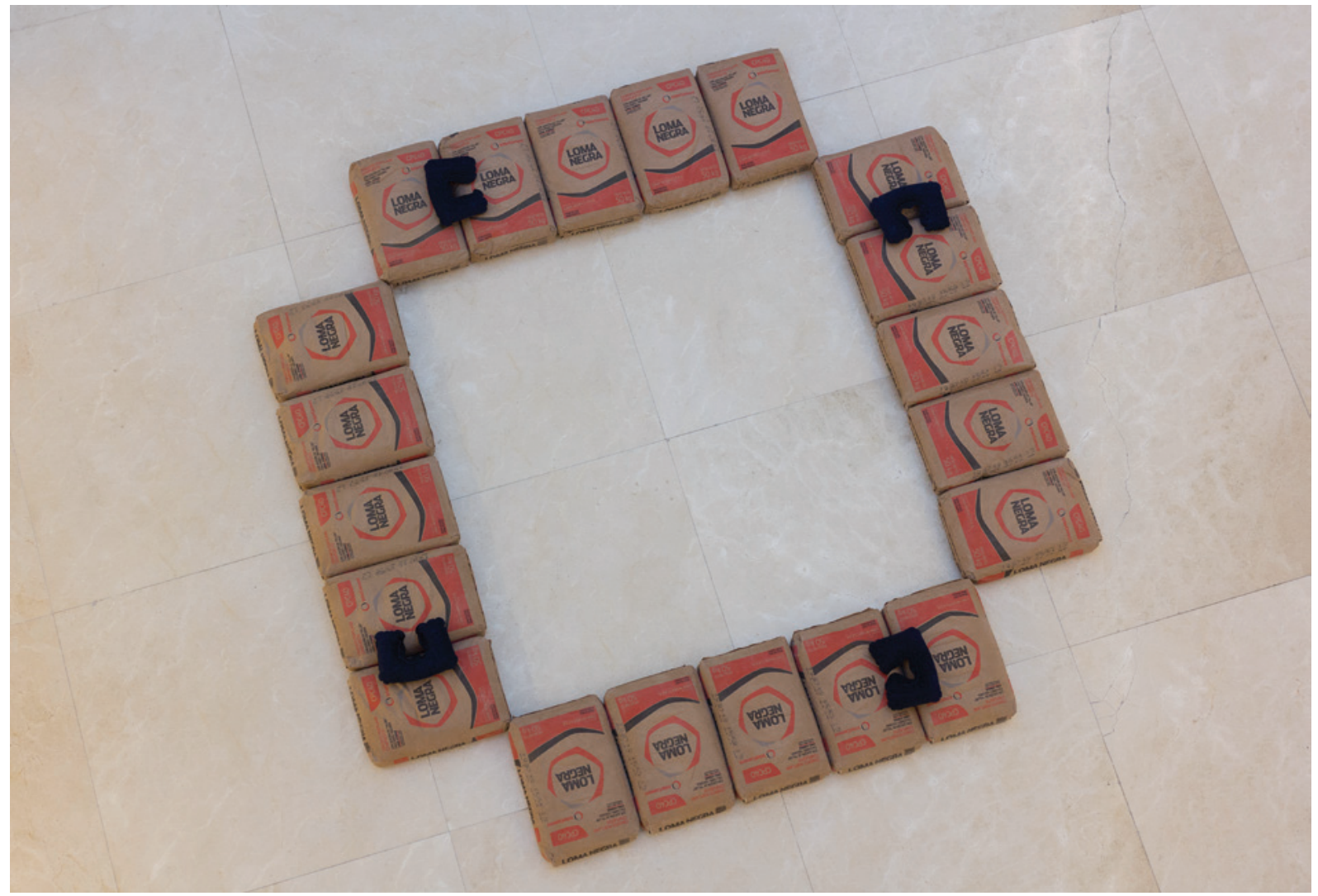

Fig.o1. Pablo Accinelli, Duración

Interna, 2018.

Fotografía de Bruno Dubner. Muestra Nubes de Paso, Museo de Arte latinoamericano de Buenos Aires

(MALBA).

\section{Duración Interna de Pablo Accinelli (2018)}

Esta obra presenta la operación (a) de Negación por hibridación de dos funcionalidades. La operación es unir dos objetos negando su funcionalidad original para constituir un nuevo objeto de uso que podría representar la unión de dos ideas y su relación dialéctica. Por su simpleza y efectividad es una de las operaciones más frecuentes en los artistas que trabajan con objetos de uso. En el caso de Duración Interna, al señalar con una almohada inflable la posibilidad de que una bolsa de cemento (que tiene una semejanza formal con un almohadón) pueda dejar de ser lo que es para constituirse en una cama o lugar de descanso, genera un diálogo dialéctico y problematización entre las ideas de trabajo y descanso. 


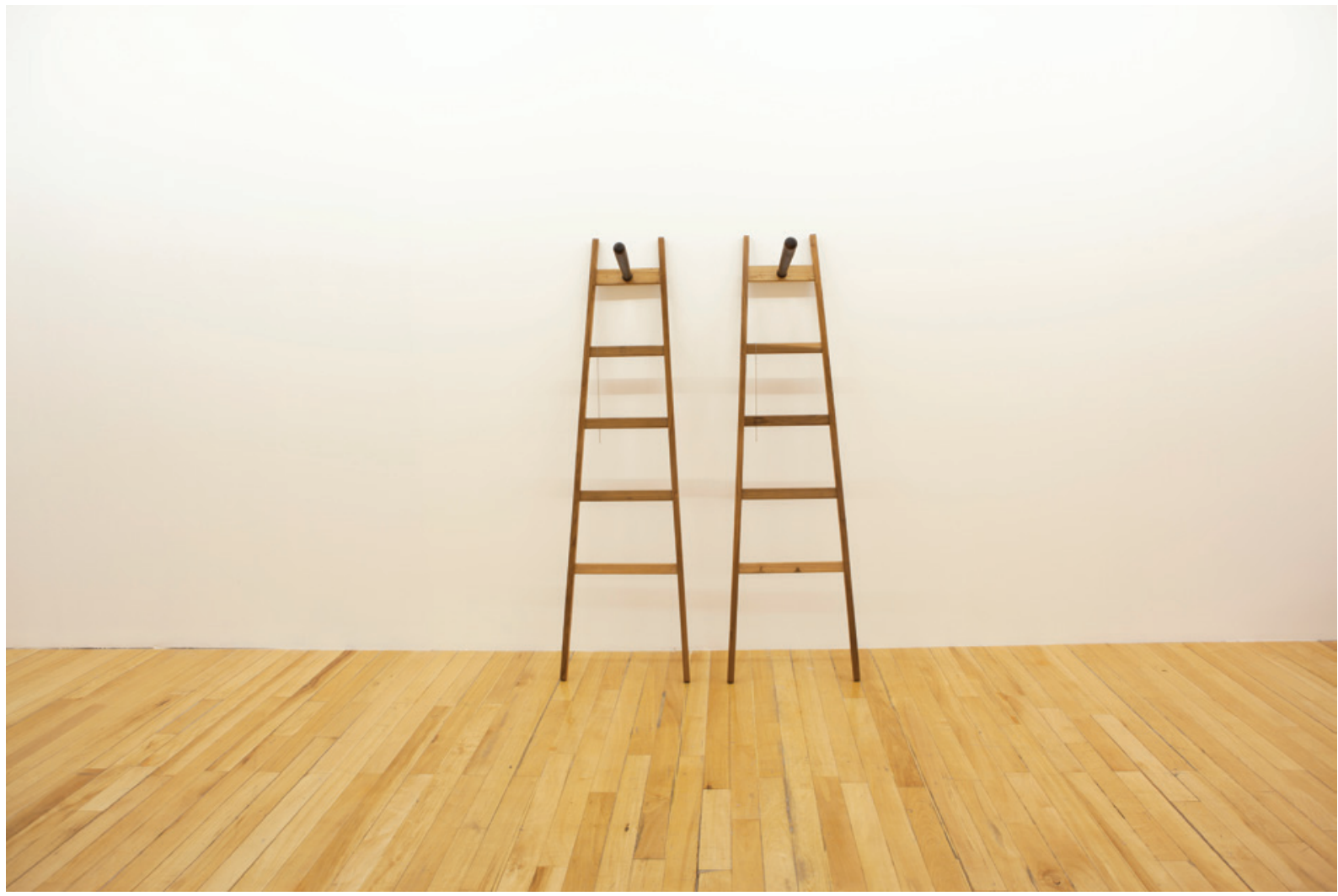

Sin titulo, de Carlos Herrera (2010/2011)

Esta obra del 2010/2011 y exhibida en 2013 de la serie Autorretrato consiste en dos escaleras de madera iguales de las cuales, en el ultimo escalón, sobresale en forma perpendicular una cachiporra de madera. Aquí vemos como Herrera aplica la misma operación que Accinelli ((a) Negación por hibridación de dos funcionalidades) esta vez utilizada para sugerir una falsa promesa de ascenso (¿social?, ¿laboral?, ¿económico?) negando la funcionalidad de la escalera poniéndola en diálogo dialéctico con la cachiporra, un objeto del ámbito de la represión que obstruye el ascenso.
Fig.02. Carlos

Herrera, Sin titulo de la serie Autorretrato, 2010/2011. Fotografía de Luis Terán. Muestra Beca Kuitca, Galería Ruth Benzacar, Buenos Aires, Argentina. 


\section{Trap, de Jorge Macchi (2018)}

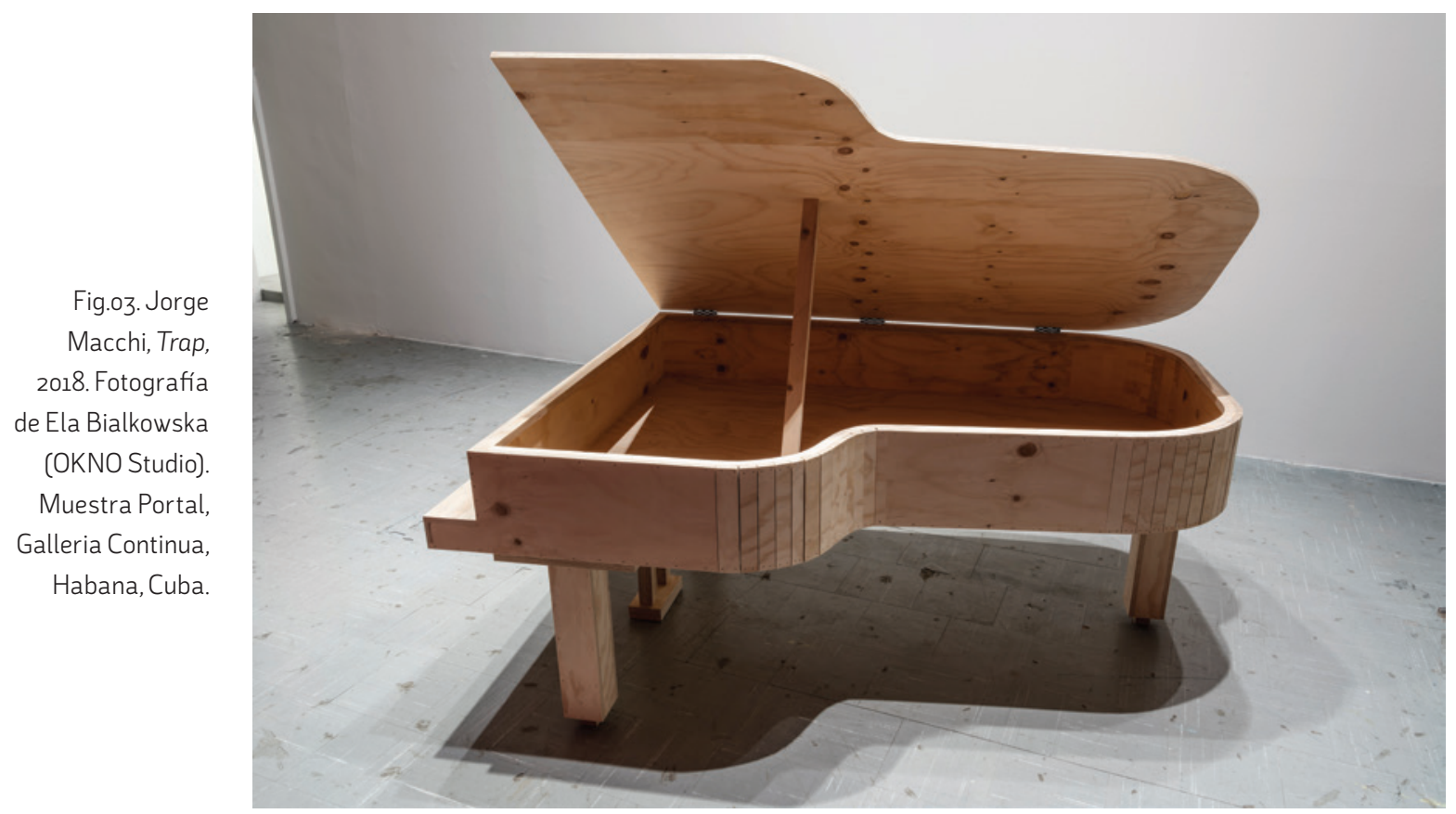

La obra consiste en un piano de cola de madera el cual no se puede ejecutar ya que sus partes funcionales no existen. La única funcionalidad que queda del piano es la posibilidad de abrir y cerrar la tapa de la cola, la cual permanece abierta a través de una madera de soporte que configura, con la caja del piano, una trampa. Aquí vemos nuevamente aplicada la operación (a) Negación por hibridación de dos funcionalidades en donde aparecen combinados en un mismo objeto, un piano, al cual se le ha negado su funcionalidad para ser combinado o convertido una trampa; un dialogo dialéctico entre las aspiraciones y mandatos de las sociedades burguesas de posguerra y una contemporaneidad en donde el género Trap nos habilita la posibilidad de que cualquiera puede ser músico cantando con auto-tune. 


\section{Las Herramientas de Moisés, de Gabriel Baggio (2017)}

Esta obra está compuesta por una serie de herramientas de carpintería y taller realizadas en cerámica esmaltada y lustre de oro, que están presentadas en forma ordenada sobre la pared. Aquí aparece la aplicación de la operación (b) Negación por materialidad no apta. Esta operación consiste en crear objetos que niegan su uso a partir de la utilización de una materialidad no apta para el cumplimiento de su funcionalidad. Esta es una tipología de operación que provoca que un aspecto, característica o atributo no evidente en relación al objeto, sea señalada por los atributos de la nueva materialidad. La cerámica esmaltada y el lustre de oro niegan la funcionalidad de las herramientas al volverlas frágiles y también aparentemente valiosas. Esos atributos hacen que el objeto no pueda cumplir la función que se espera de ellos mientras dicen algo en relación a lo que para nosotros podrían significar hoy las actividades que representan.

La operación (b) Negación por materialidad no apta, en este caso es aplicada a cada uno de los objetos de uso que componen la pieza, pero a su vez, en forma grupal, Baggio pone en funcionamiento la operación (c) Negación por situación de reposo ordenado. Esta operación consiste en presentar objetos de uso como un conjunto ordenado, negando la funcionalidad de los mismos por su situación de reposo organizado como en un panel de taller o una vitrina. Cuando se aplica esta operación se suele hacer referencia a la representación de una actividad, la potencialidad de una acción, y/o a un ámbito determinado.

En el texto de Federico Baeza titulado Elogio del uso se destaca la importancia del contacto y la cita en la obra de Baggio, tanto en los relatos que convoca como en los procedimientos técnicos con los que construye su obra (desde los objetos, saberes y prácticas que le son cercanos). Otro término sobre el que trabaja Baggio es el de la reivindicación de las artes del hacer, del habitar, del conversar, del cocinar, del hablar, del leer. En este mismo sentido se rescatan las artes débiles del decorar, las artes aplicadas, la Ornamentaría. Baggio ha puesto en primer plano prácticas estéticas cotidianas como cocinar, tejer, habitar, conversar, decorar y antiguos oficios en desuso, como procesos alternativos al consumo, prácticas que 'producen sin capitalizar', es decir, prácticas que no acumulan ni generan ganancia económica (Baeza, 2010). 


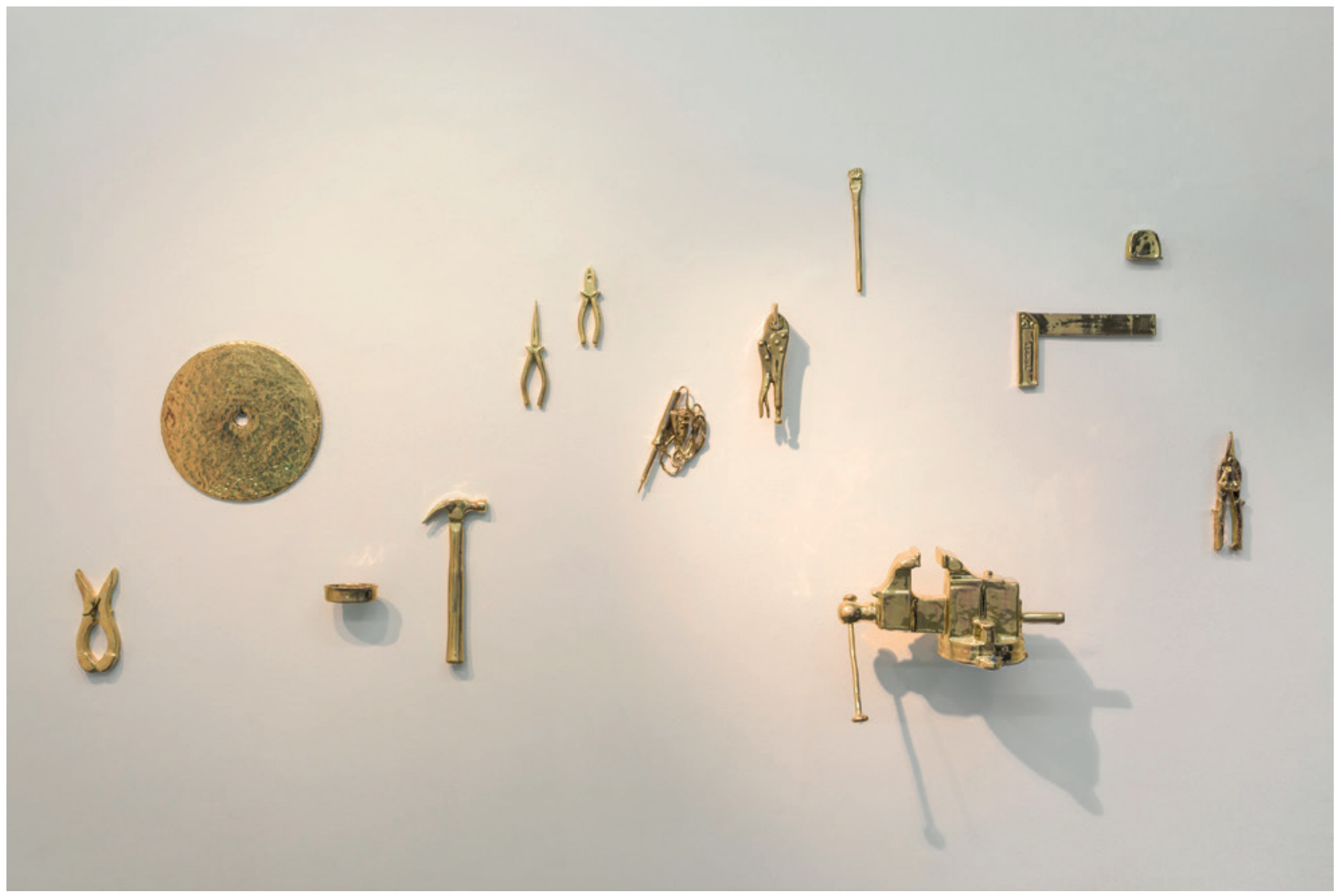

Fig.04. Gabriel Baggio, Las Herramientas de Moises, 2017. Fotografía de Agustín Rojas. Muestra Lo que Queda, Galería Hache, Buenos Aires, Argentina. 


\section{Reacción, de Jorge Macchi (2010)}

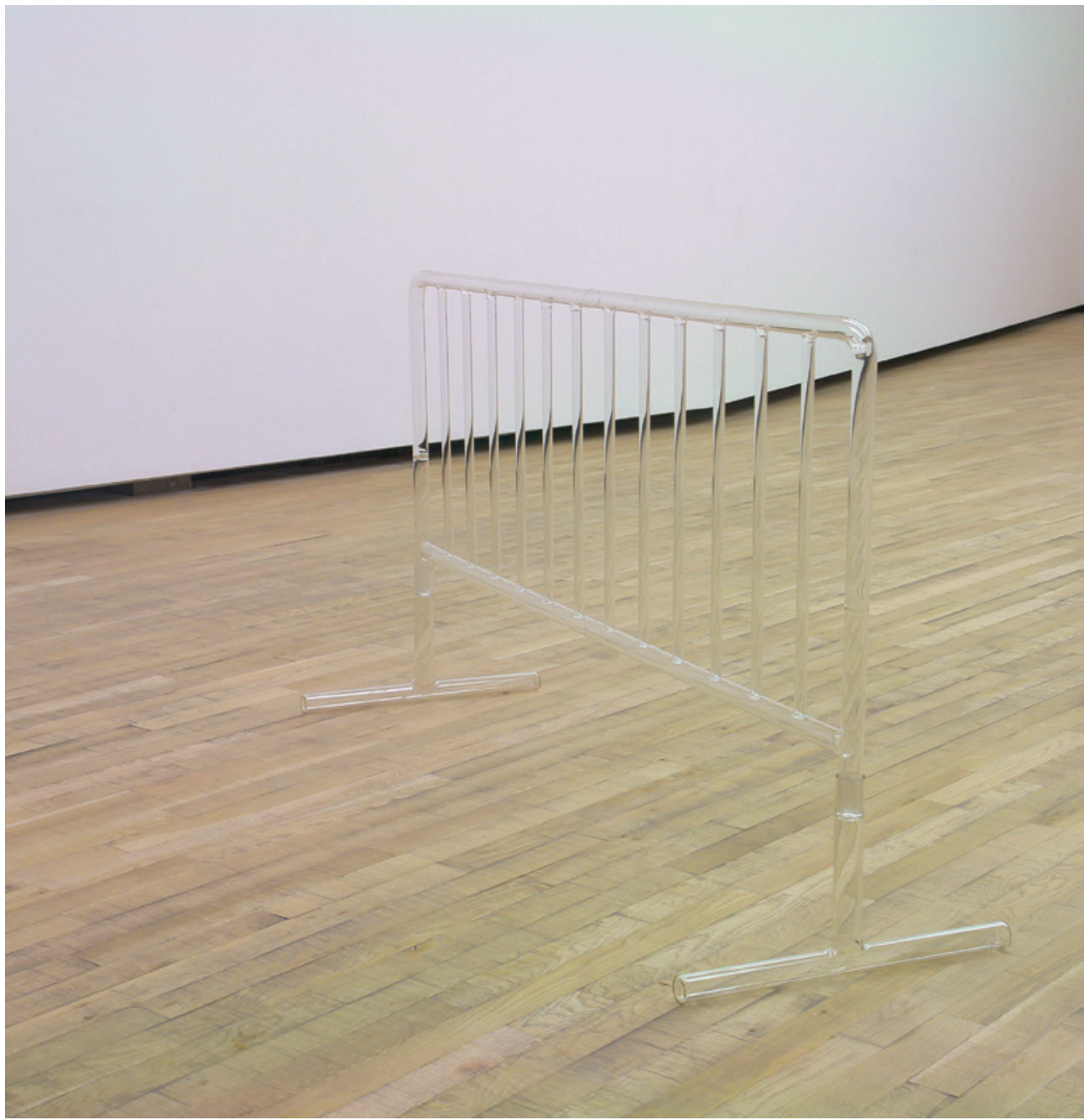

Fig.05. Jorge

Macchi, Reacción,

2010. Fotografía

de Jorge Macchi.

Muestra Of Bridges

\& Borders, Fundación

PROA, Buenos

Aires, Argentina.

Esta obra consiste en una valla policial realizada en vidrio soplado aplicando la misma operación (b) Negación por materialidad no apta que Baggio utiliza en sus herramientas doradas. En los textos que acompañan la presentación de la obra Reacción de Jorge Macchi en el marco de la muestra realizada en Fundación PROA y en el libro Of Bridges $\&$ Borders, Segismond de Vajay afirma que esta obra podría interpretarse como la fragilidad del poder, o como la autoridad invisible que siempre nos persigue (De Vajay, 2009), o sea, atributos no evidentes de lo que el objeto, en su versión normativa, representa. 


\section{La voz del interior, de Andrés Aizicovich (2016)}

Fig.o6. Andrés

Aizicovich, La voz del interior, 2016.

Fotografía de Natalia Labaké. Centro Cultural Recoleta, Buenos Aires, Argentina.

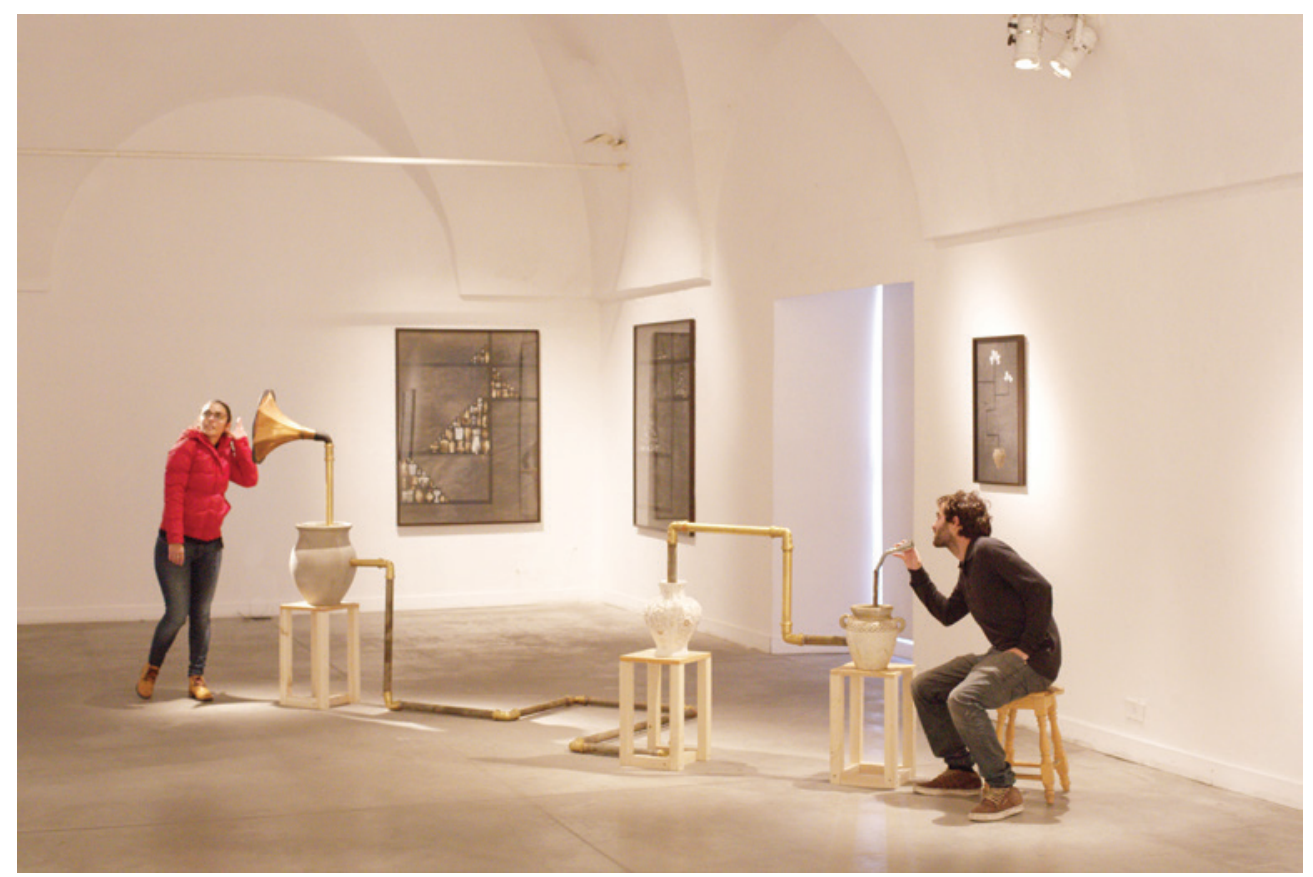

Se trata de una obra conformada por una secuencia lineal de objetos de uso como jarrones, banquitos, y duchadores, que se conectan entre sí a través de caños para terminar conectados a la bocina de un gramófono. En esta obra de Aizicovich aparece la aplicación de la operación (d) Negación por re-funcionalización de objetos en secuencia. Esta consiste en presentar varios objetos de uso (más de dos) vinculados en una secuencia como partes constructivas de acuerdo a sus vinculaciones funcionales y formales, negando y re-funcionalizando el uso original de cada una de las partes para constituir una nueva entidad. La aplicación de esta operación deriva en ensamblajes que podrían hacer referencia a la representación de procesos singulares, que en el caso especifico de esta obra podría ser un proceso de comunicación en el contexto del hogar, una obra que conecta historias, lazos familiares, mandatos y movilidad social.

La voz del interior es una instalación de obras objetuales y pinturas que pone en escena el diálogo intergeneracional entre las personas. Algunas de las temáticas que aparecen desplegadas en la muestra son: la transmisión oral del saber, las historias y los lazos familiares, la herencia cultural y los objetos que van pasando de generación en generación.

Aizicovich sumerge al espectador en un viaje hacia la mirada de los antepasados, buceando en el significado de crecer en una familia de clase media con sus mandatos de movilidad social a través de la ilustración y el acceso al mundo a través de las enciclopedias. (Arteinformado, 2016) 


\section{Sin título, de Ernesto Ballesteros (2017)}

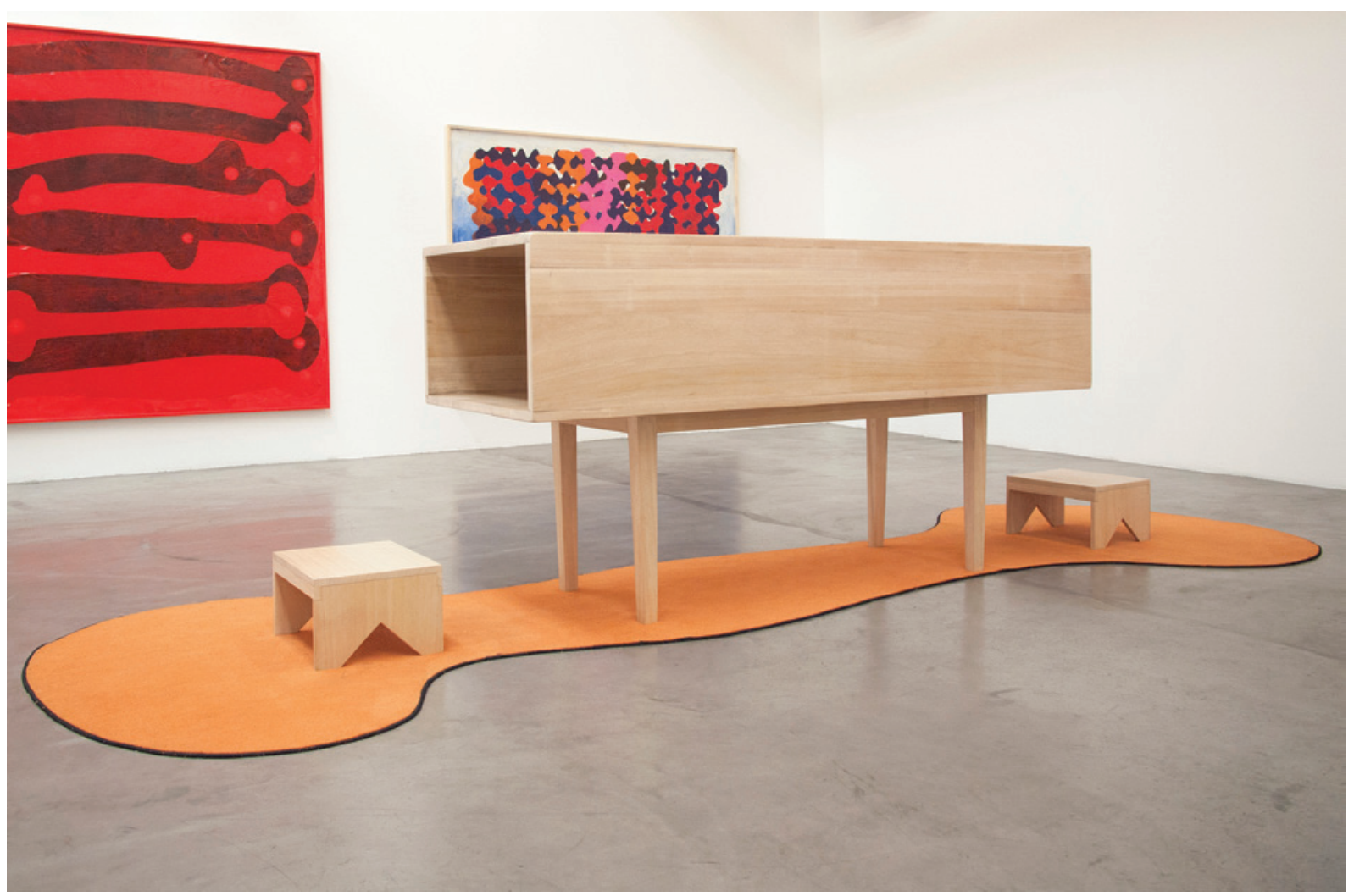

En la obra de Ballesteros, que fue parte de su muestra Conjetura, se aplica la misma

Fig.07. Ernesto Ballesteros,

Sin titulo, 2017. Fotografía de Ernesto Ballesteros. Muestra Conjetura, Galería Ruth Benzacar, Buenos Aires, Argentina.

\begin{abstract}
El deseo de realizar objetos lo llevó a inventar un mueble. Desde lejos, en la mitad de la sala y sobre una alfombra, se divisa un prisma rectangular de sólida madera sobre cuatro patas con unos banquitos en los extremos. Al sentarse, la mirada atraviesa el hueco abierto que tiene la medida de una pantalla de TV y llega al otro lado, también abierto. Sentada en el otro banquito puede haber otra persona que, distante nos mira o, simplemente, nada. La experiencia, lejos de evocar el ruido de la TV o el atractivo ciberespacio, retrotrae al silencio de los claustros medievales, acentúa el abismo que separa el mundo real del virtual. Mundos que hoy se confunden, mayormente indiferenciados (Martínez Quijano, 2016).
\end{abstract}




\section{Morir no es posible, de Mariana Telleria (2013)}
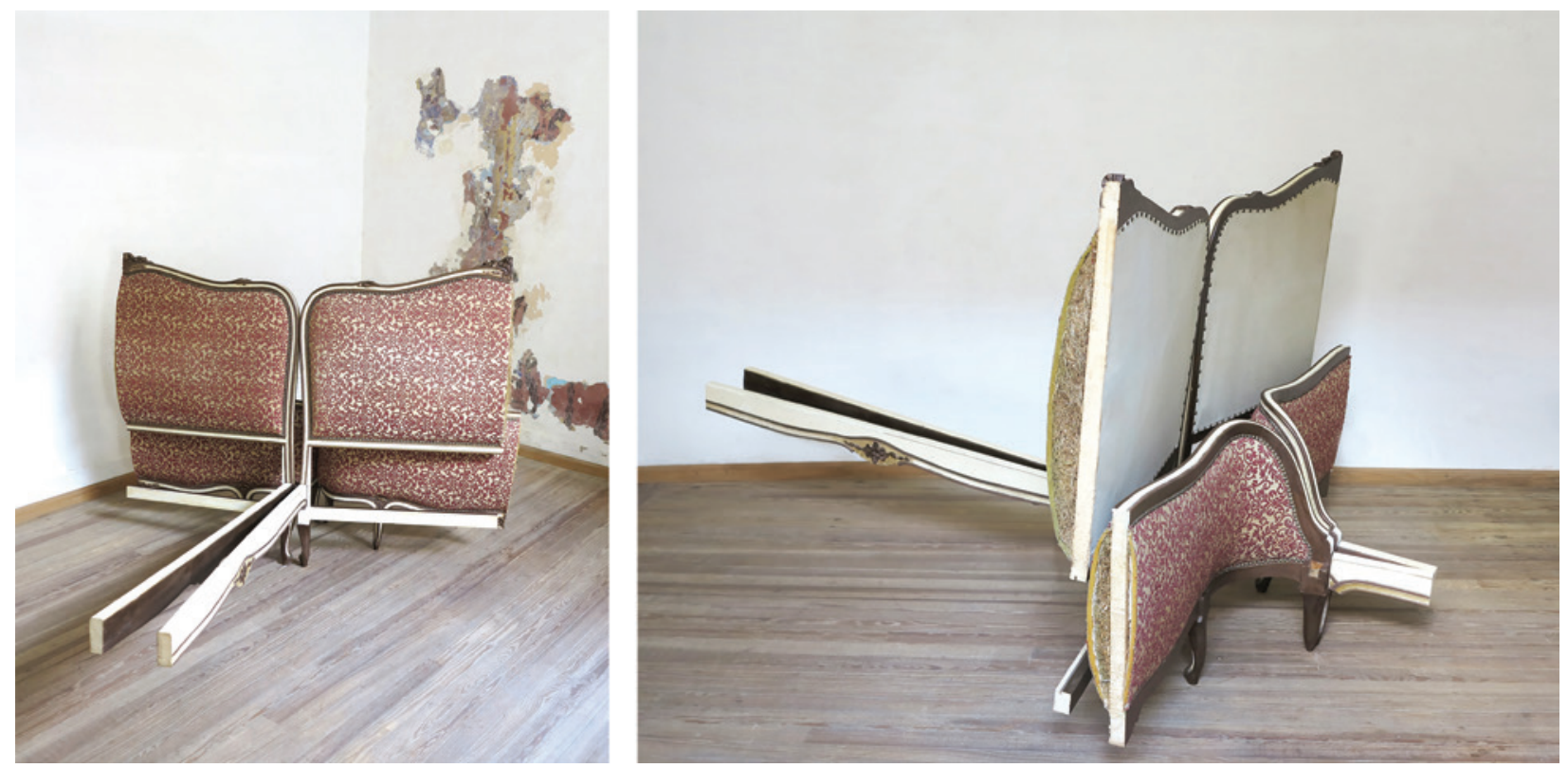

Fig.08. Mariana

Telleria, Morir no es posible, 2013.

Fotografía de Mariana Telleria.

Cortesía de la artista y galería Ruth Benzacar.
Esta obra, de la serie Buscando a Cristo en todos lados, consiste en una cama de dos plazas que es cortada por la mitad y vuelta a unir en posición invertida y con sus partes inferiores de madera formando una cruz. Aquí Telleria aplica la operación (e) Negación por desmembramiento y re-configuración que consiste en crear objetos a partir de la acción de segmentar en partes y reconfigurar objetos de uso negando su funcionalidad original. Esta acción de desmembramiento y reconfiguración, como operación formal, podría hacer referencia al develamiento de un secreto o esencia oculta en el objeto desmembrado o lo que este representa. En el libro El nombre de un país, que documenta el envío argentino a la $58 \mathrm{va}$ Bienal de Venecia, Florencia Battiti escribe sobre la obra de Mariana Telleria afirmando que en sus trabajos hay un afán por deshabituar la mirada de la funcionalidad de los objetos y arrancarles sus secretos ya que, al deshabituar los usos se deshabitúan también las significaciones, se derrumba el orden establecido, y aparece lo poético (y lo político) de su trabajo. También afirma que en cada objeto se encuentra encriptado su propio valor subversivo o la latencia de otra identidad (Battiti, 2019). 


\section{Sin titulo (estructura para mesita) (2010) y Powerful lessons, (2015), de Eugenia Calvo}
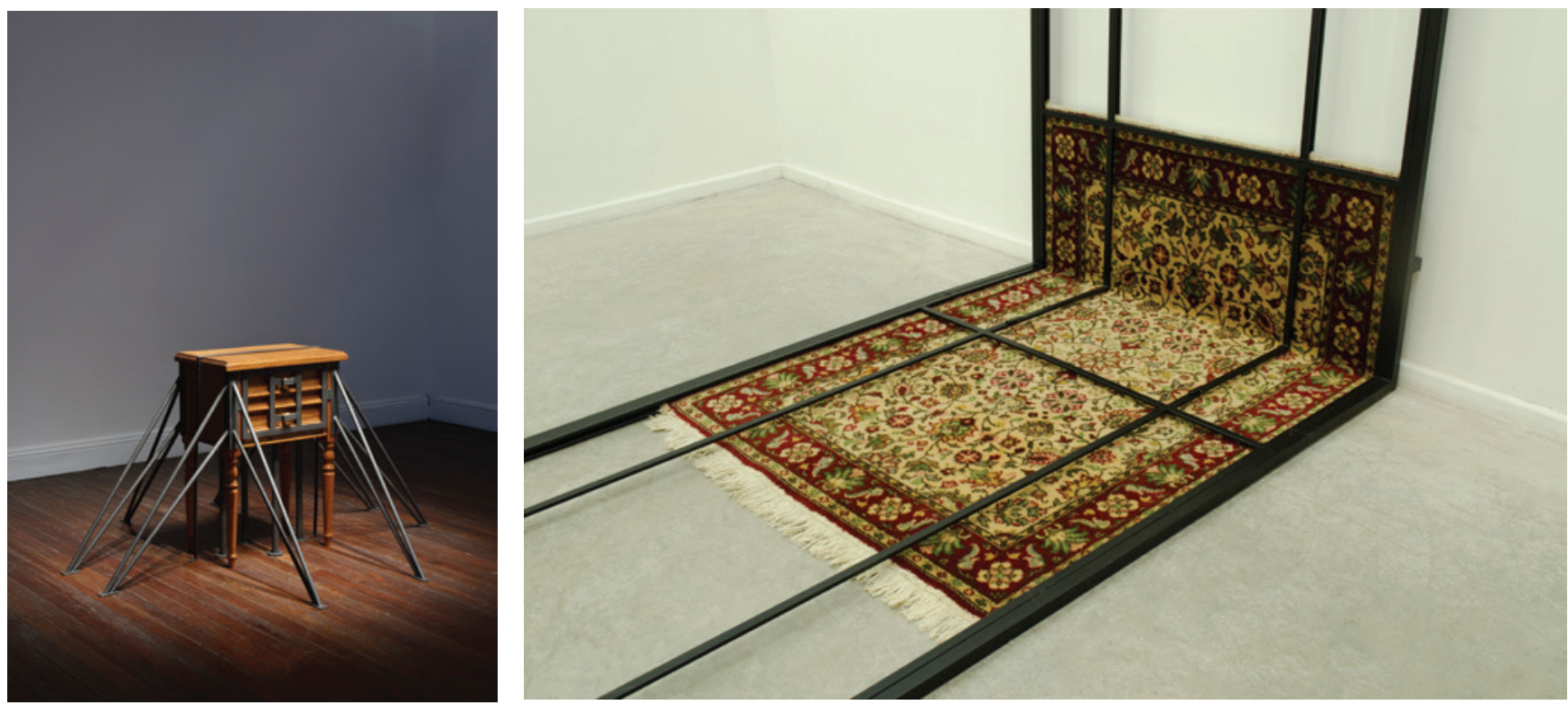

Estas dos obras aplican la operación (f) Negación por restricción física de la funcionalidad, que consiste en presentar objetos de uso cuya funcionalidad es negada a través de la restricción física de la función. Esta operación genera objetos que podrían hacer referencia a la representación de la posibilidad de rebeldía, autonomía, peligrosidad, o posible voluntad propia de los objetos y lo que ellos representan (la materialidad del dispositivo de restricción opera como par dialéctico con el objeto de forma similar a la de la operación (a)).

La obra \#9, S/T (estructura para mesita) de la serie S/T [estructuras para mobiliario] consiste en una mesa pequeña de madera que es aprisionada y sujetada al suelo por una estructura de hierro.

En el texto de Santiago García Navarro (Universos Bajo Amenaza sobre la obra de Eugenia Calvo, en el marco de la muestra Resplandores de 2017 en el Centro Cultural Recoleta) afirma que la obra de Calvo se trata de un trabajo en el cual el espacio doméstico se presenta como un universo bajo amenaza. Los procedimientos para generar este espacio doméstico bajo amenaza varían, pero de alguna forma siempre implican una alteración de la función característica de los enseres, mobiliario o elementos decorativos del hogar de modo de transformarlos en otra cosa y, al hacerlo, generar situaciones de inestabilidad (García Navarro 2017).

La obra \#10, Powerful Lessons, consiste en una alfombra que quiere desplazarse de su lugar normativo (el piso) hacia la pared y es restringida por una estructura-jaula de hierro.
Fig.og. Eugenia Calvo, S/T (estructura para mesita), 2010. Fotografía de Fabián Cañas. Galería 713 Arte Contemporáneo, Buenos Aires, Argentina.

Fig.10. Eugenia Calvo,

Powerful Lessons, 2010. Fotografía de Eugenia Calvo. Galeria Mal del Archivo,

Rosario, Argentina. 

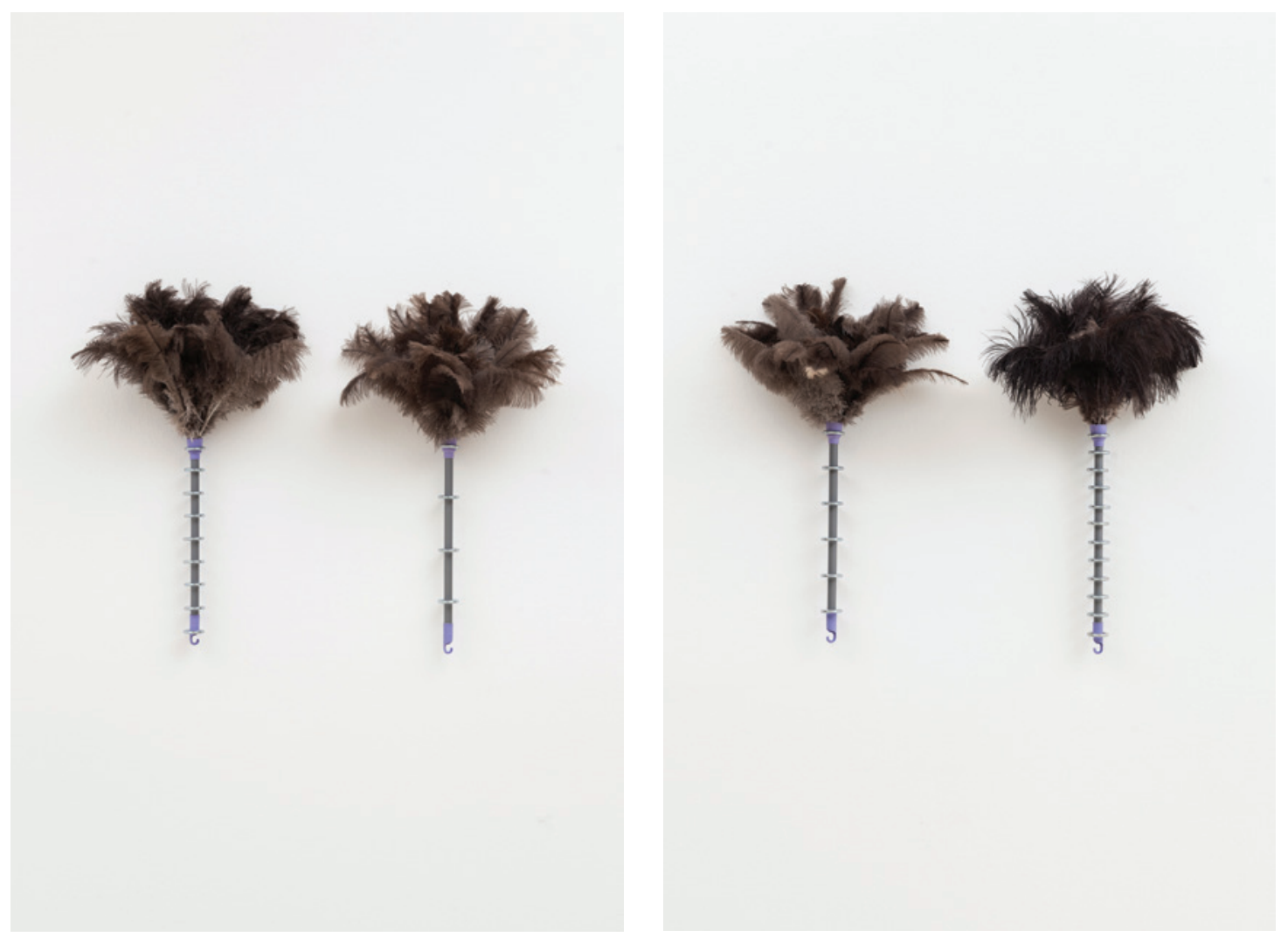

Fig.11 y 12. Pablo Accinelli, $4 \mathrm{~cm}, 9$ $\mathrm{cm}, y 6 \mathrm{~cm}, 3 \mathrm{~cm}$, 2018. Fotografías de

Catalina Romero. Muestra Nubes de Paso, Museo de Arte

Latinoamericano de Buenos Aires (MALBA), Argentina.
$4 \mathrm{~cm}, 9 \mathrm{~cm}$, y $6 \mathrm{~cm}, 3 \mathrm{~cm}$, de Pablo Accinelli (2018)

Ambas obras son similares y consisten, cada una, en dos plumeros aprisionados contra la pared por una serie de pitones de hierro. La diferencia entre ambas obras son la cantidad y distancia entre los pitones que aprisionan a los plumeros. Aquí se ve de nuevo la operación (f) Negación por restricción física de la funcionalidad, que señala el posible deseo de autonomía de estos objetos, a quienes no sólo se les niega la posibilidad de salir volando con sus plumas, sino que también se les niega el uso normativo para el cual fueron concebidos originalmente. 


\section{Conclusiones}

Si bien estas prácticas artísticas de desplazamiento y/o intervención de objetos de uso cotidiano pueden rastrearse, en términos historiográficos, a los orígenes del arte conceptual, pareciera que mantienen una especial vigencia en las prácticas contemporáneas tanto a nivel local como internacional. Una de las preguntas que permanentemente me planteo, al reconocer que estas operaciones de negación y desplazamiento de las funcionalidades de los objetos no son un fenómeno exclusivamente contemporáneo, es porqué los artistas lo siguen haciendo hoy en día, cuál es la relevancia actual de estos gestos, especialmente en el contexto del arte contemporáneo argentino.

Para entender esto en clave contemporánea no podemos evitar notar que, a partir de la aparición de las interfaces gráficas de usuario en las computadoras personales, la masificación del uso de la Internet y, especialmente en forma acelerada a partir de la presencia ubicua de dispositivos móviles de telecomunicación, hemos sido testigos de la desaparición de una enorme cantidad de objetos de uso que antes nos rodeaban, objetos que han migrado del plano físico tridimensional al plano digital a través de aplicaciones informáticas. En este sentido, quizás la presencia de objetos de uso que ya no son necesarios, que van desapareciendo, y la sospecha de que los que aun persisten y nos rodean también pueden llegar a desaparecer, generan en los artistas este deseo de re-funcionalizarlos para un uso crítico, estético o para la preservación de una memoria, aprovechando el anclaje de esa idea normativa sobre su razón de ser, que aun opera en los receptores y usuarios de una forma fantasmática.

Por otro lado, esta época atravesada por descubrimientos científicos y tecnológicos que plantean cambios paradigmáticos en casi todos los órdenes de nuestras vidas, obligan a re-evaluar nuestro lugar de sujetos en relación a los objetos. Algo que antes era un simple objeto hoy puede transformarse en amenaza o en sujeto, hoy puede tomar decisiones por nosotros y hasta reemplazarnos en nuestro trabajo. Estos profundos cambios que vienen produciéndose en las expectativas de la gente, en la vida cotidiana, en las instituciones, y en el mundo laboral, son el contexto habitual de los artistas y desde el cual se producen actualmente este tipo de obras.

Por lo tanto, uno de los temas que se ponen en juego en este encuentro entre las disciplinas proyectuales y estas prácticas artísticas contemporáneas es la cuestión de la técnica en tanto asunto cultural, un encuentro que demanda una mirada sobre las transformaciones vividas dentro de la cultura material en general, en relación con las vidas cotidianas particulares. En este sentido un referente importante para abordar esta cuestión podría ser la obra de Richard Sennett: La corrosión del carácter: las consecuencias personales del trabajo en el nuevo capitalismo (2000), El respeto: sobre la dignidad del hombre en un mundo de desigualdad (2003), La cultura del nuevo capitalismo (2006), y especialmente El Artesano (2009), en donde Sennett propone, como objetivo general, explorar una serie de 'falsas líneas divisorias' que 
han tenido una marcada presencia en la cultura occidental: la distinción entre mano y cabeza, práctica y teoría, técnica y expresión, artesano y artista, productor y usuario.

Parecería que los objetos de uso y el lenguaje del diseño se convirtieron en un vehículo ineludible y universal a la hora de producir el reconocimiento de cier tos aspectos concretos que distinguen la vida de las personas, así como para convertir situaciones particulares, y también sociales, en experiencias plausibles de ser narradas.

Sería interesante, para los especialistas en diseño que se ocupan de la ideación de los objetos de uso, prestar atención sobre estas prácticas artísticas que ponen en juego, cuestionan y problematizan esa supuesta primacía de la función y de los aspectos materiales como parámetro central para establecer la relación que el hombre tiene con los objetos. Las formas cómo estos objetos intervenidos por artistas nos definen (a los sujetos) a partir de la autonomía que adquieren, puede constituirse en una punta de lanza para que el campo del diseño, a partir de diversas operaciones formales y conceptuales, generen nuevos modos de entrega de los objetos a la conciencia de los usuarios, a través de fenomenologías que exceden muchas veces las posibilidades que se podrían plantear desde la práctica tradicional del diseño. 


\section{Listado bibliográfico}

ARTEINFORMADO, (2016). Descripción de la exposición La voz del interior. Consultado en: https://www. arteinformado.com/agenda/f/la-voz-del-interior-122534\#ai-collapseDescription

BAEZA, F. (2010). Elogio del Uso. Texto de catálogo de muestra en Fundación F. J. Klemm. Consultado en: http://www.gabrielbaggio.com/obras.html

BATTITI, F. (2019). El nombre de un país / Mariana Telleria, Buenos Aires, Argentina: Ministerio de Relaciones Exteriores y Culto, Dirección General de Asuntos Culturales.

BAUDRILLARD, J. (1969). El sistema de los objetos. México: Siglo XXI.

BÜRDEK, B. E. (2002 [1994]). Historia, teoría y práctica del diseño industrial. Barcelona, España: Editorial Gustavo Gili, SL.

DE VAJAY, S. (2009). Of Bridges \& Borders, Buenos Aires, Argentina: Kultur Buro Buenos Aires. GARCía NAVARRO, S. (2007). Universos Bajo Amenaza en Fichas\#23 - Eugenia Calvo - Juego de Dormitorio. CeDIP, Centro de Documentación, Investigación y Publicaciones del Centro Cultural Recoleta. Consultado en: Cibertronic - Revista de Artes Mediáticas / Universidad de Tres de Febrero http://www.untref.edu.ar/cibertronic/lopublico_loprivado/ notalo/Ficha-23.pdf

GroYs, B. (2014). Volverse Publico. Buenos Aires, Argentina: Caja Negra Editora.

GOMBRICH, E. H. (2003 [1963]). Meditaciones sobre un caballo de juguete. Madrid, Editorial Debate.

HUDEK, A. (2014). The Object. Documents of Contemporary Art. Cambridge M.A., MIT Press-Whitechapel Gallery. "Introduction-Detours of objects" pp. 14-27.

MARTíneZ QuiJAno, A. (2016). Ballesteros, creador de mundos paralelos. Ámbito. Buenos Aires, Argentina. Consultado en: https://www.ambito.com/edicion-impresa/ballesteros-creador-mundos-paralelos-n3963255

RINKER, D. (2006). El diseño de producto no es arte en Modelos de ulm - modelos post-ulm / Hochschule für gestaltung ulm 1953-1968, Catálogo de la exposición conmemorativa de los 50 años de la fundación de la HfG, Ulm, Alemania: IFA - Institut für Auslands-beziehungen e.V./Stadt Ulm - Ulmer Museum - HfG Archiv ULM. 


\section{Listado documental}

ACCINELLI, P. (2018). Obra titulada Duración Interna de la muestra Nubes de Paso. MALBA. Consultado en: https:// malba.org.ar/evento/pablo-accinelli/\#prettyphoto[group]/7/

ACCINELLI, P. (2018). Obras tituladas 4cm, $9 \mathrm{~cm}$ y $6 \mathrm{~cm}$, $3 \mathrm{~cm}$ de la muestra Nubes de Paso. MALBA. Consultado en: https://malba.org.ar/evento/pablo-accinelli/\#prettyphoto[group]/7/

AIZICOVICH, A. (2016). Escultura de la muestra La voz del interior. Centro Cultural Recoleta. Consultado en: https:// www.flickr.com/photos/andaiz/sets/72157676356833565/

BAGGIO, G. (2011). Obra titulada Las Herramientas de Moises. Esculturas en cerámica esmaltada y lustre de oro. Consultado en: http://www.gabrielbaggio.com/obras.html

BALLeSteros, E. (2017). Obra sin titulo, de la muestra Conjetura. Escultura en madera. Consultado en: https:// verrev.org/2016/12/02/conjetura-ernesto-ballesteros/

CALVO, E. (2011). Obra titulada S/T (estructura para mesita), de la serie S/T (Estructuras para mobiliario). Escultura en hierro y madera. Medidas $184 \mathrm{~cm} \times 75 \mathrm{~cm} \times 135 \mathrm{~cm}$. Consultado en: http://eugeniacalvo.com/es-ar/ trabajos-seleccion/s-t-estructuras-para-mobiliario/

CALVO, E. (2015). Obra titulada Powerful Lessons, Estructura en hierro y alfombra. Medidas $300 \mathrm{~cm} \times 100 \mathrm{~cm} \times 300$ cm. Consultado en: http://eugeniacalvo.com/es-ar/trabajos-seleccion/powerful-lessons/

Herrer A, C. (2013). Obra sin título, de la muestra Trabajo Nocturno. Escultura en madera. Consultado en: http:// www.herreracarlos.com.ar/Muestra.html?Obra=11

MACCHI, J. (2018). Obra titulada Trap. Escultura en madera. Medidas $61 \mathrm{~cm} \times 214 \mathrm{~cm} \times 168 \mathrm{~cm}$. Consultado en: https://www.jorgemacchi.com/es/obras/620/trap

MACCHI, J. (2010). Obra titulada Reacción. Escultura sobre vidrio soplado. Medidas 210cm x 102cm x 6ocm. Consultado en: http://proa.org/esp/exhibition-of-bridges-and-borders-jorge-macchi-1.php

TELLERIA, M. (2013). Obra titulada Morir no es posible (de la serie Buscando a Cristo en todos lados). Escultura realizada a partir de una cama fragmentada. Medidas $140 \mathrm{~cm}$ x $180 \mathrm{~cm}$ x $250 \mathrm{~cm}$. Consultado en: https://www.artsy. net/artwork/mariana-telleria-morir-no-es-posible-de-la-serie-buscando-a-cristo-en-todos-lados 